\title{
Extracorporeal life support during pregnancy
}

\author{
Sarah A. Moore, MD, ${ }^{a}$ Charles A. Dietl, MD, ${ }^{b}$ and Denise M. Coleman, MD
}

\begin{abstract}
Objectives: To review the literature on extracorporeal life support (ECLS) during pregnancy to determine its efficacy and safety for the mother and fetus.

Methods: A comprehensive literature search was obtained from MEDLINE via PubMed.gov and from ScienceDirect.com using the following search queries: ECLS and pregnancy, extracorporeal membrane oxygenation (ECMO) and pregnancy, ECMO and H1N1 influenza, acute respiratory distress syndrome (ARDS) and pregnancy, pregnancy and H1N1 influenza, and Extracorporeal Life Support Organization registry.

Results: Our literature search produced 332 articles for review. A total of 45 patients treated with ECLS or ECMO during pregnancy were reported in 26 publications. Postpartum patients were not included. Indications for ECLS were severe H1N1 influenza with ARDS $(\mathrm{n}=33)$, other ARDS $(\mathrm{n}=8)$, cardiogenic $\operatorname{shock}(\mathrm{n}=3)$, and cardiac arrest $(\mathrm{n}=1)$. The mean gestational age was 26.5 weeks (range, 12-38 weeks), and the median duration of ECLS was 12.2 days (range, 1-57 days). The survival rate was $77.8 \%$ (35 of 45 ) for mothers and $65.1 \%$ (28 of 43) for fetuses. In addition, we report a 25 -year-old pregnant patient with hantavirus cardiopulmonary syndrome unresponsive to pressors and inotropes. The patient was placed on venoarterial ECMO for 72 hours, recovered without complications, and delivered a healthy infant. The mother and son remain asymptomatic 6 years later.
\end{abstract}

Conclusions: ECLS during pregnancy is effective and relatively safe for the mother and fetus. The first successful use of ECLS in a pregnant patient with life-threatening hantavirus cardiopulmonary syndrome is being reported together with this review. (J Thorac Cardiovasc Surg 2016;151:1154-60)

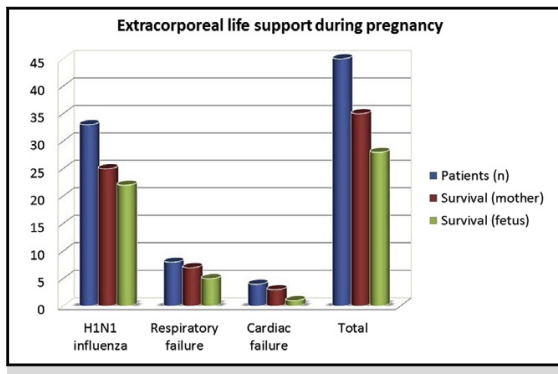

Maternal and fetal survival of all reported cases of ECLS during pregnancy.

\section{Central Message}

Extracorporeal life support during pregnancy is effective and relatively safe for the mother and fetus.

\section{Perspective}

The aim of this study was to review the literature on extracorporeal life support (ECLS) during pregnancy to determine its efficacy and safety. A comprehensive literature search revealed that the use of ECLS or extracorporeal membrane oxygenation during pregnancy has been reported in only 45 patients. The survival rate was $77.8 \%$ for mothers and $65.1 \%$ for fetuses. In conclusion, ECLS is effective and relatively safe during pregnancy.

See Editorial Commentary page 1161.
A previously healthy 25 -year-old pregnant patient presented in respiratory failure was diagnosed with hantavirus cardiopulmonary syndrome (HCPS). She remained severely hypoxic despite mechanical ventilation, and developed worsening hypotension refractory to inotropic and vasoactive medications. The patient was placed on venoarterial (V-A) extracorporeal life support (ECLS) for 72 hours, after which she recovered without complications and delivered a healthy infant. A review of our case is what led us to examine the maternal and fetal outcomes of ECLS during pregnancy.

From the ${ }^{\mathrm{a} D e p a r t m e n t}$ of Surgery, ${ }^{\mathrm{b}}$ Division of Cardiothoracic Surgery, Department of Surgery, and ${ }^{\mathrm{c}}$ Division of Pediatric Critical Care, Department of Pediatrics, University of New Mexico Health Sciences Center, Albuquerque, NM.

Received for publication Sept 14, 2015; revisions received Nov 27, 2015; accepted for publication Dec 12, 2015; available ahead of print Jan 27, 2016.

Address for reprints: Charles A. Dietl, MD, Division of Cardiothoracic Surgery, Department of Surgery, University of New Mexico, 2-ACC, MSC 105610 , Albuquerque, NM 87131 (E-mail: cdietl@ comcast.net).

$0022-5223 / \$ 36.00$

Copyright (c) 2016 by The American Association for Thoracic Surgery

http://dx.doi.org/10.1016/j.jtcvs.2015.12.027
Previous publications on ECLS and extracorporeal membrane oxygenation (ECMO) during pregnancy consist of case reports or small case series, the vast majority involving pregnant women with severe H1N1 influenza complicated with acute respiratory distress syndrome (ARDS). The aim of the present study was to review the available literature on all reported cases requiring ECLS during pregnancy, not including postpartum patients, to determine its efficacy and safety for the mother and fetus.

\section{METHODS}

A comprehensive literature search was obtained from MEDLINE via PubMed.gov and from ScienceDirect.com using the following search queries: ECLS and pregnancy; ECMO and pregnancy; ECMO and H1N1

Scanning this QR code will take you to the article title page. 


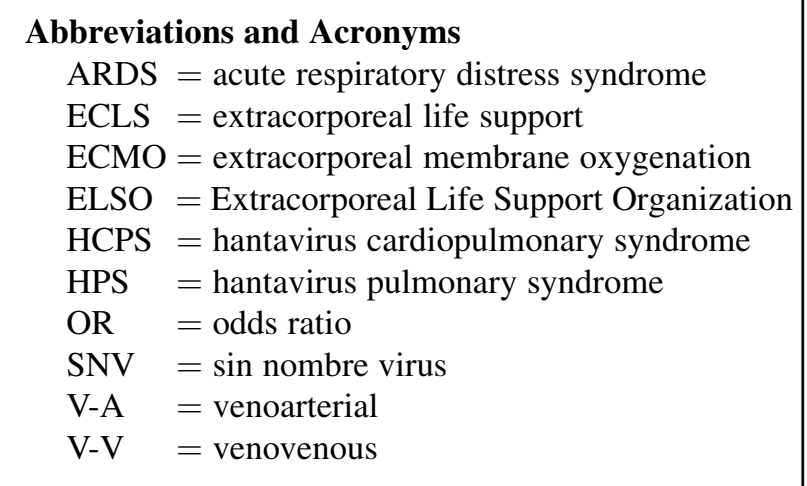

influenza; ARDS and pregnancy; pregnancy and H1N1 influenza; Extracorporeal Life Support Organization (ELSO) Registry.

According to the policies of the Institutional Review Board at the University of New Mexico, this study did not require review by the institutional Human Research Review Committee.

\section{Statistical Analysis}

Fisher's exact test was used to detect any statistically significant difference in the observed maternal and fetal survival associated with the diagnosis, gestational age, or technique of ECLS. A $P$ value $<.05$ was considered to indicate significance.

\section{RESULTS}

We followed PRISMA guidelines in our systematic review of the literature (Figure 1). Our literature search produced 332 articles for review. Only those publications that reported the use of ECLS or ECMO during pregnancy were selected for review. Postpartum patients were not included. A total of 45 patients treated with ECLS or ECMO during pregnancy were reported in 26 publications, which are listed chronologically in Table 1. The first 7 publications on ECLS or ECMO during pregnancy were case reports published between 1991 and 2007. ${ }^{1-7}$ These were profoundly hypoxic pregnant women who needed ECLS because of respiratory failure secondary to varicella pneumonia $(n=2)$, ARDS $(n=4)$, or right heart failure secondary to primary pulmonary hypertension $(\mathrm{n}=1)^{5}$

The most common indication for ECLS during pregnancy was severe H1N1 influenza complicated with ARDS $(\mathrm{n}=33)$. Fourteen articles that included pregnant women treated with ECMO during the 2009 H1N1 pandemic were published between 2009 and 2014. ${ }^{8-21}$ The Australia and New Zealand Extracorporeal Membrane Oxygenation Influenza Investigators published 2 reports; to avoid duplication, only the 7 patients listed in the report by Nair and colleagues ${ }^{15}$ are included in Table 1. The largest series, published by Dubar and colleagues $^{13}$ from France, reported 11 pregnant women treated with ECMO for severe ARDS secondary to severe H1N1 influenza.
Four additional publications on the use of ECLS during pregnancy included 5 patients, including 1 case of hypoxic cardiac arrest, ${ }^{22} 1$ case of ARDS of unknown origin, ${ }^{23} 1$ case of refractory cardiac arrhythmia with cardiogenic shock, ${ }^{24} 1$ case of mycoplasma ARDS, ${ }^{25}$ and 1 case of cardiogenic shock likely of viral origin. ${ }^{25}$

The mean gestational age of the 45 patients was 26.5 weeks (range, $12-38$ weeks). Only 1 patient $(2.2 \%)$ was placed on ECLS during the first trimester, 19 $(42.2 \%)$ were placed during the second trimester, and 25 $(55.6 \%)$ were placed during the third trimester. Venovenous $(\mathrm{V}-\mathrm{V})$ cannulation was used in 41 patients with severe respiratory failure, and 4 patients with both cardiac and respiratory failure underwent $\mathrm{V}$-A femoral cannulation for ECLS. The median duration of ECLS was 12.2 days (range, 1-57 days).

The most common ECLS-related complication was bleeding. Major bleeding was reported in 7 articles. $^{3,10,15,17,21,22,25}$ Nair and colleagues ${ }^{15}$ reported major bleeding in $57.1 \%$ ( 4 of 7 ) of their pregnant women while on ECMO, which necessitated packed red blood cell transfusion in relatively large volumes (median volume transfused, $3500 \mathrm{~mL}$ ) and was the main cause of death. The bleeding sites were intracranial or multiple sites in cases with fatal hemorrhage, and uterine or pulmonary in cases of nonfatal bleeding. ${ }^{15}$ Other bleeding problems included hemothorax, , $^{3,10,21,22}$ upper gastrointestinal hemorrhage, ${ }^{17}$ nonfatal fetal intracranial hemorrhage, ${ }^{17}$ vaginal bleeding, ${ }^{25}$ and bleeding from the cannulation and tracheostomy sites. $^{25}$ Other reported ECLS-related complications include hemolysis $^{14}$; cannula dislodgment ${ }^{3}$; ineffective flow rate resulting from uterine compression, which improved after emergency cesarean section ${ }^{7}$; and nosocomial infections, including bloodstream, respiratory, urinary tract, and line-related infections. ${ }^{15}$

According to our literature review, ECLS during pregnancy is associated with survival rates of $77.8 \%$ (35 of 45) in mothers and $65.1 \%$ (28 of 43) in fetuses (Table 1). Three maternal deaths were caused by multiorgan system failure, 1 death was attributed to infection, and cause of death was not reported for the other patients. Of the 15 fetal deaths, 5 were intrauterine deaths occurring during ECLS, 3 were stillbirths, 1 occurred during cesarean section delivery, and 1 was an elective abortion. The causes of death were not mentioned for 5 fetal deaths. The maternal and fetal outcomes of all reported cases of ECLS during pregnancy are summarized in Table 2.

A review of maternal and fetal mortality shows that 8 of the 33 pregnant women placed on ECMO during the 2009 H1N1 pandemic did not survive (odds ratio [OR], $24.2 \%$ ), compared with 2 maternal deaths among the 12 pregnant women placed on ECLS for other indications $(\mathrm{OR}, 16.7 \%)(P=.50329844)$. Nine of the 33 fetal deaths occurred in the pregnant women placed on ECMO during 


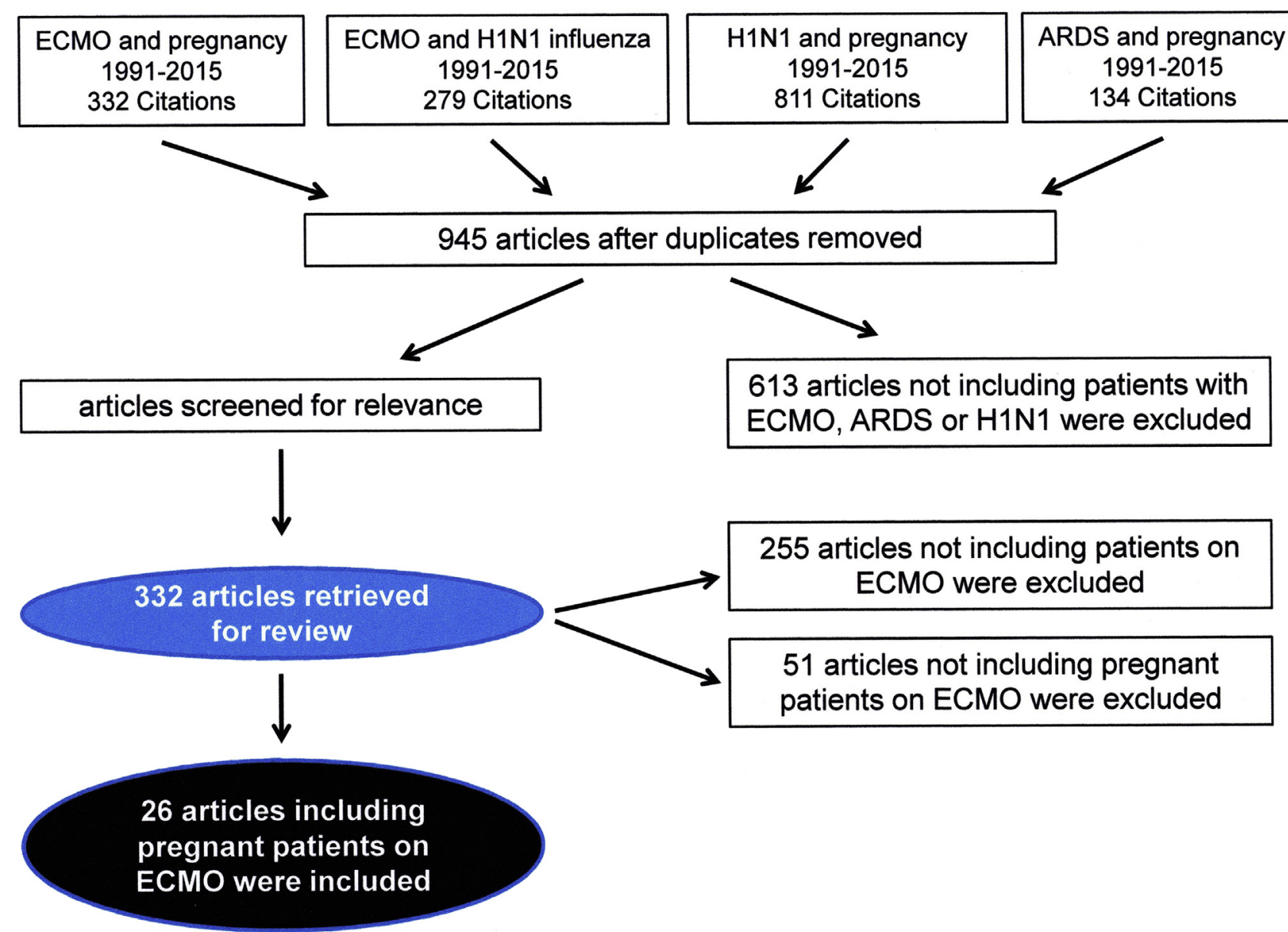

FIGURE 1. Flow diagram of the study. ECMO, Extracorporeal membrane oxygenation; H1N1, influenza; ARDS, acute respiratory distress syndrome.

the 2009 H1N1 pandemic (OR, 27.3\%), compared with 6 fetal deaths among the 12 pregnant women placed on ECLS for other indications (OR, 50.0\%) $(P=.34712174)$.

Five maternal deaths occurred among the 19 women placed on ECLS during the second trimester (OR, $26.3 \%$ ), and 5 maternal deaths occurred among 25 women placed on ECLS during the third trimester (OR, 20.0\%) $(P=.73634496)$. One of the 15 fetal deaths occurred in the sole patient placed on ECLS during the first trimester (OR, 100\%), whereas 8 fetal deaths occurred among the 19 patients placed on ECLS during the second trimester (OR, 42.1\%) and 5 fetal deaths occurred among the 25 patients placed on ECLS during the third trimester (OR, 20.0\%) $(P=.34549835)$. The gestational age of 1 mother whose fetus died during ECMO support was not reported. ${ }^{14}$

Nine maternal deaths occurred among the 41 patients placed on V-V ECMO (OR, 21.9\%), compared with 1 death among the 4 patients placed on V-A ECMO (OR, 25.0\%) $(P=.77950425)$. Among the 15 fetal deaths reported, 12 occurred among the 39 patients placed on V-V ECMO
(OR, 30.8\%), and 3 occurred in 4 patients placed on V-A ECMO $(\mathrm{OR}, 75.0 \%)(P=.35970671)$.

\section{DISCUSSION}

In a previous review article, Sharma and colleagues ${ }^{25}$ reported cases of ECLS during pregnancy and the postpartum period published between 2009 and 2014. The authors observed that the overall maternal survival was $80 \%$ and fetal survival was $70 \%$. In contrast, our present study consisted of a comprehensive literature search on all of the reported cases of ECLS only during pregnancy, excluding all postpartum patients.

The prevalence of ARDS during pregnancy has been estimated as 16 to 70 cases per 100,000 pregnancies. $^{26}$ During pregnancy, nonobstetric causes of ARDS include sepsis due to pyelonephritis, pneumonia, intracerebral hemorrhage, blood transfusion, and trauma. Another nonobstetric etiology for ARDS was reported during the 2009 H1N1 pandemic, and several studies have reported that pregnant patients are at higher risk for developing ARDS. Overall mortality for both the mother and fetus is 
TABLE 1. Reported cases of ECLS/ECMO during pregnancy

\begin{tabular}{|c|c|c|c|c|c|c|c|}
\hline Report & $\begin{array}{c}\text { No. of } \\
\text { patients }\end{array}$ & $\begin{array}{c}\text { Gestational } \\
\text { age }\end{array}$ & Indication & ECLS type & $\begin{array}{c}\text { ECLS } \\
\text { duration }\end{array}$ & $\begin{array}{c}\text { Outcome, } \\
\text { mother }\end{array}$ & Outcome, fetus \\
\hline Clark et al $^{1}$ & 1 & $12 \mathrm{wk}$ & Varicella pneumonia & $\mathrm{V}-\mathrm{V}$ & $90 \mathrm{~h}$ & Alive & Death (elective abortion) \\
\hline Greenberg and Moore ${ }^{2}$ & 1 & 26 wk & ARDS (pneumonia) & V-A & $28 \mathrm{~d}$ & Alive & Alive (preterm) \\
\hline Lee et $\mathrm{al}^{3}$ & 1 & $17 \mathrm{wk}$ & Varicella pneumonia & $\mathrm{V}-\mathrm{V}$ & $57 \mathrm{~d}$ & Death (MOSF) & Death (stillborn abortion) \\
\hline King et $\mathrm{al}^{4}$ & 1 & $25 \mathrm{wk}$ & ARDS (pneumonia) & $\mathrm{V}-\mathrm{V}$ & $60 \mathrm{~h}$ & Alive & Alive (delivery at $31 \mathrm{wk}$ ) \\
\hline Satoh et $\mathrm{al}^{5}$ & 1 & $18 \mathrm{wk}$ & $\mathrm{RHF} / \mathrm{PPH}$ & V-A & $19 \mathrm{~d}$ & Death (MOSF) & Death $(\mathrm{C}-\mathrm{S})$ \\
\hline Cunningham et $\mathrm{al}^{6}$ & 1 & $23 \mathrm{wk}$ & ARDS & $\mathrm{V}-\mathrm{V}$ & $72 \mathrm{~h}$ & Alive & Alive (preterm) \\
\hline Parkins et $\mathrm{al}^{7}$ & 1 & $32 \mathrm{wk}$ & ARDS (pneumonia) & $\mathrm{V}-\mathrm{V}$ & $13 \mathrm{~d}$ & Alive & Alive (C-S at $32 \mathrm{wk}$ ) \\
\hline Scriven et $\mathrm{al}^{8}$ & 1 & $33 \mathrm{wk}$ & ARDS (H1N1) & $\mathrm{V}-\mathrm{V}$ & - & Alive & Alive (C-S at $33 \mathrm{wk}$ ) \\
\hline Singh et $\mathrm{al}^{9}$ & 1 & $18 \mathrm{wk}$ & ARDS (H1N1) & $\mathrm{V}-\mathrm{V}$ & $48 \mathrm{~h}$ & Death & Intrauterine death \\
\hline Oluyomi-Obi et al $^{10}$ & 2 & Mean, 29 wk & ARDS (H1N1) & $\mathrm{V}-\mathrm{V}$ & - & Death & Intrauterine death \\
\hline 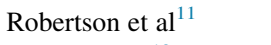 & 1 & $24 \mathrm{wk}$ & ARDS (H1N1) & $\mathrm{V}-\mathrm{V}$ & $17 \mathrm{~d}$ & Alive & Alive (C-S at $38 \mathrm{wk}$ ) \\
\hline Kunstyr et $\mathrm{al}^{12}$ & 1 & $22 \mathrm{wk}$ & ARDS (H1N1) & $\mathrm{V}-\mathrm{V}$ & $14 \mathrm{~d}$ & Alive & Alive (preterm) \\
\hline Dubar et $\mathrm{al}^{13}$ & 11 & Mean, 33 wk & ARDS (H1N1) & $\mathrm{V}-\mathrm{V}$ & Mean, $8 \mathrm{~d}$ & $\begin{array}{l}\text { Alive, } \mathrm{n}=9 ; \\
\text { death, } \mathrm{n}=2\end{array}$ & Alive, $\mathrm{n}=9 ;$ death, $\mathrm{n}=2$ \\
\hline Holzgraefe et $\mathrm{al}^{14}$ & 3 & - & ARDS (H1N1) & $\mathrm{V}-\mathrm{V}$ & - & Alive, $n=3$ & Alive, $\mathrm{n}=2 ;$ death, $\mathrm{n}=1$ \\
\hline Nair et al ${ }^{15}$ & 7 & Mean, 23 wk & ARDS (H1N1) & $\mathrm{V}-\mathrm{V}$ & Mean, $11 \mathrm{~d}$ & $\begin{array}{l}\text { Alive, } \mathrm{n}=5 \\
\quad \text { death, } \mathrm{n}=2\end{array}$ & Alive, $\mathrm{n}=5 ;$ death, $\mathrm{n}=2$ \\
\hline Courouble et al ${ }^{16}$ & 1 & $28 \mathrm{wk}$ & ARDS (H1N1) & $\mathrm{V}-\mathrm{V}$ & $14 \mathrm{~d}$ & Alive & Alive (delivery at $32 \mathrm{wk}$ ) \\
\hline Panarello et a ${ }^{17}$ & 1 & $25 \mathrm{wk}$ & ARDS (H1N1) & $\mathrm{V}-\mathrm{V}$ & $35 \mathrm{~d}$ & Alive & Neuro def (C-S at $30 \mathrm{wk})$ \\
\hline Bowkalow et $\mathrm{al}^{18}$ & 1 & $20 \mathrm{wk}$ & ARDS (H1N1) & $\mathrm{V}-\mathrm{V}$ & $28 \mathrm{~d}$ & Death (MOSF) & Death (stillborn abortion) \\
\hline Grasselli et al ${ }^{19}$ & 1 & $27 \mathrm{wk}$ & ARDS (H1N1) & $\mathrm{V}-\mathrm{V}$ & $13 \mathrm{~d}$ & Alive & Alive (delivery at $38 \mathrm{wk}$ ) \\
\hline Takeda et $\mathrm{al}^{20}$ & 1 & - & ARDS (H1N1) & $\mathrm{V}-\mathrm{V}$ & - & - & - \\
\hline Seczyńska et $\mathrm{al}^{21}$ & 1 & $28 \mathrm{wk}$ & ARDS (H1N1) & $\mathrm{V}-\mathrm{V}$ & $21 \mathrm{~d}$ & Alive & Alive (C-S at 28 wk) \\
\hline Grimme et $\mathrm{al}^{22}$ & 1 & 19 wk & Cardiac arrest & $\mathrm{V}-\mathrm{V}$ & $8 \mathrm{~d}$ & Alive & Death (during ECLS) \\
\hline Ngatchou et a ${ }^{23}$ & 1 & $32 \mathrm{wk}$ & ARDS & $\mathrm{V}-\mathrm{V}$ & $2 \mathrm{~d}$ & - & - \\
\hline Sim et $\mathrm{al}^{24}$ & 1 & 26 wk & Cardiogenic shock & V-A & $7 \mathrm{~d}$ & Alive & Death (during ECLS) \\
\hline Sharma et $\mathrm{al}^{25}$ & 2 & $35 \mathrm{wk}$ & Mycoplasma & $\mathrm{V}-\mathrm{V}$ & $5 \mathrm{~d}$ & Alive & Alive (normal delivery) \\
\hline & & $34 \mathrm{wk}$ & Cardiogenic shock & V-A & $6 \mathrm{~d}$ & Alive & Death (stillborn abortion) \\
\hline Total & 45 & Mean, $26.5 \mathrm{wk}$ & & $\begin{array}{r}\mathrm{V}-\mathrm{V}, \mathrm{n}=41 \\
\mathrm{~V}-\mathrm{A}, \mathrm{n}=4\end{array}$ & Mean, $12.2 \mathrm{~d}$ & $\begin{array}{l}77.8 \%(35 \text { of } 45) \\
\text { survived }\end{array}$ & $65.1 \%(28$ of 43$)$ survived \\
\hline
\end{tabular}

$E C L S$, Extracorporeal life support; $V-V$, venovenous; $A R D S$, acute respiratory distress syndrome; $V$ - $A$, venoarterial; $M O S F$, multiorgan system failure; $R H F$, right heart failure; $P P H$, primary pulmonary hypertension; $C-S$, cesarean section; $H 1 N 1$, influenza.

high, and significant morbidity can persist even after initial recovery. ${ }^{26}$ Mortality due to ARDS during pregnancy is not significantly different than that in nonpregnant patients $(23 \%-39 \%)$ and is associated with marked perinatal morbidity and a high rate of fetal loss $(23 \%)$. Multiple organ dysfunction syndrome has been reported as the most common cause of maternal death. ${ }^{26}$
The overall approach to treating ARDS during pregnancy closely follows that for the general population with ARDS and includes providing supportive care while identifying and treating the underlying cause. For patients failing conventional lung-protective mechanical ventilation, alternative approaches include the use of high-frequency oscillatory ventilation, lung recruitment maneuvers, prone

TABLE 2. Summary of maternal and fetal outcomes of all reported cases of ECLS/ECMO during pregnancy

\begin{tabular}{|c|c|c|c|c|c|c|}
\hline Indication for ECLS & $\begin{array}{c}\text { No. of } \\
\text { patients }\end{array}$ & $\begin{array}{c}\text { Gestational } \\
\text { age, wk, mean }\end{array}$ & ECLS type & $\begin{array}{l}\text { ECLS duration, } \\
\text { d, mean }\end{array}$ & Outcome, mother & Outcome, fetus \\
\hline $\mathrm{H} 1 \mathrm{~N} 1$ influenza & 33 & 27.8 & $\mathrm{~V}-\mathrm{V}$ & 12.2 & $75.7 \%$ ( 25 of 33 ) survived & $\begin{array}{l}70.9 \%(22 \text { of } 31) \\
\text { survived }\end{array}$ \\
\hline Respiratory failure (other causes) & 8 & 24.4 & $\mathrm{~V}-\mathrm{V}$ & 11.9 & $\begin{array}{l}87.5 \%(7 \text { of } 8) \\
\text { survived }\end{array}$ & $\begin{array}{l}62.5 \%(5 \text { of } 8) \\
\text { survived }\end{array}$ \\
\hline Cardiac and respiratory failure & 4 & 26.0 & V-A & 15.0 & $\begin{array}{l}75.0 \% \text { ( } 3 \text { of } 4) \\
\text { survived }\end{array}$ & $\begin{array}{l}25.0 \%(1 \text { of } 4) \\
\text { survived }\end{array}$ \\
\hline Total & 45 & 26.5 & $\begin{array}{l}\mathrm{V}-\mathrm{V}, \mathrm{n}=41 \\
\mathrm{~V}-\mathrm{A}, \mathrm{n}=4\end{array}$ & 12.2 & $\begin{array}{l}77.8 \% \text { ( } 35 \text { of } 45) \\
\text { survived }\end{array}$ & $\begin{array}{l}65.1 \% \text { ( } 28 \text { of } 43) \\
\text { survived }\end{array}$ \\
\hline
\end{tabular}

ECLS, Extracorporeal life support; $H 1 N 1$, influenza; $V$ - $V$, venovenous; $V$-A, venoarterial. 
positioning, and inhaled nitric oxide. None of these modalities has been demonstrated to reduce mortality in the general ARDS population, however. ${ }^{26}$ Strategies commonly used in nonpregnant patients with ARDS might not be acceptable in pregnant patients, because permissive hypercapnia may have significant fetal effects, and although prone positioning may be possible in early pregnancy, it has obvious limitations in late pregnancy. ${ }^{27}$

Corticosteroid use has been controversial, particularly with respect to the dosage and timing of administration. Improvements in oxygenation have been reported with the use of low- to moderate-dose methylprednisolone $(<2.5 \mathrm{mg} / \mathrm{kg} /$ day $)$; however, 1 study reported no improvement in outcomes with the use of corticosteroids in parturient patients with H1N1 influenza and nonimmunocompromised patients with ARDS. ${ }^{26}$

In the past, the use of ECMO in adults with refractory hypoxemia was fraught with complications, and its use in the management of ARDS was controversial. However, recent improvements in vascular cannulas and membrane oxygenators have made V-V ECMO simpler, less invasive, and safer than before. The $2009 \mathrm{H} 1 \mathrm{~N} 1$ pandemic led to increased application of ECMO to treat severe influenza pneumonia with refractory hypoxemia. ${ }^{28}$

The published experience in the adult population has shown improved survival in patients who received mechanical ventilation for $<5$ days before the initiation of ECMO. Maternal and fetal outcomes also appear to be better in patients receiving mechanical ventilation for $<7$ days before initiation of ECMO. ${ }^{6}$

Another important consideration to keep in mind in pregnant women who require ECLS is the fact that during late pregnancy, the enlarged uterus may compress the vena cava, leading to such adverse effects as reduced maternal cardiac output and fetal oxygenation. This condition may explain the difficulty faced when advancing a femoral venous cannula through the inferior vena cava into the right atrium. Ngatchou and colleagues ${ }^{23}$ proposed using a $15^{\circ}$ to $30^{\circ}$ left lateral tilt position during femoral cannula insertion to reduce aortocaval compression in late pregnancy; however, this maneuver was not necessary in our patient, who presented at 18 weeks gestation.

In summary, our comprehensive literature review found an overall maternal survival rate of $77.8 \%$ ( 35 of 45 ) for all 45 pregnant women reported in the literature who underwent ECLS support during pregnancy, and a fetal survival rate of $65.1 \%$ (28 of 43 ) (Table 2 and Figure 2). These outcomes compare favorably with the overall $55 \%$ survival for adult respiratory ECLS published in the 2012 ELSO Registry report. ${ }^{29}$ The question of outcomes from the use of ECMO in the pregnant population was not addressed in that 2012 report. ${ }^{29}$

In addition to the 45 cases of ECLS during pregnancy published in the literature, here we report the first successful

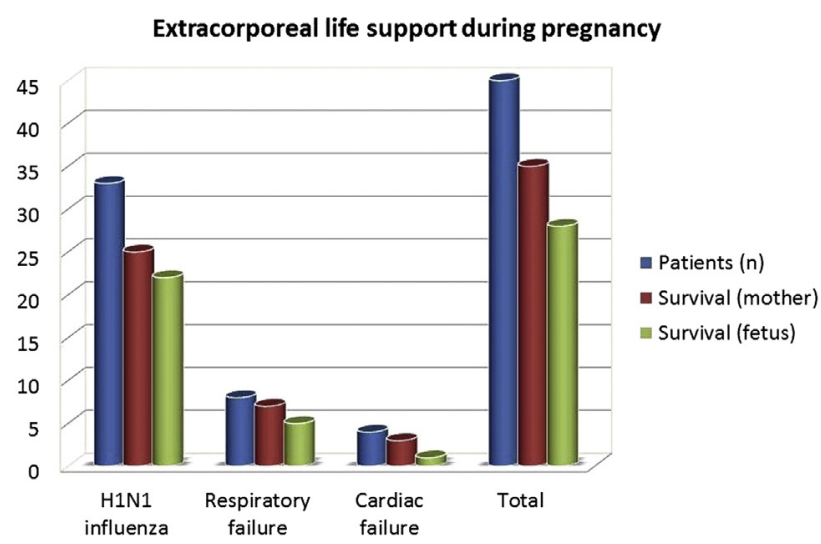

FIGURE 2. Maternal and fetal survival of all reported cases of extracorporeal life support during pregnancy. $H 1 N 1$, Influenza.

use of ECLS for HCPS during pregnancy. A previously healthy 25-year-old woman (gravida 2, para 1) who presented at 18 weeks gestation with a 5-day history of flu-like symptoms and respiratory distress. Her history was remarkable for a recent heavy dust exposure while moving boxes. Her respiratory status deteriorated over 24 hours, necessitating intubation. She was subsequently transferred to our tertiary care facility with a suspected diagnosis of HCPS. Her initial chest radiograph showed bilateral diffuse patchy infiltrates (Figure 3). The peripheral blood smear review met 4 of the 5 screening criteria for hantavirus, which include thrombocytopenia, myelocytosis, hemoconcentration, lack of significant toxic granulation in neutrophils, and $>10 \%$ of lymphocytes with immunoblastic features. ${ }^{30}$ An immunoblot assay for rapid detection of sin nombre virus (SNV) antibodies was positive.

The patient remained severely hypoxic despite mechanical ventilation, and developed worsening hypotension refractory to inotropic and vasoactive medications. The decision was made to place her on V-A ECLS. After intravenous heparin $(200 \mathrm{U} / \mathrm{kg})$ was administered, cannulation was performed using an open technique through the right common femoral artery and vein using $15 \mathrm{~F}$ and $27 \mathrm{~F}$ Bio-Medicus cannulas (Medtronic, Minneapolis, Minn), respectively. An $8 \mathrm{~F}$ distal perfusion cannula was placed into the right superficial femoral artery to prevent limb ischemia. The patient was connected to the ECLS circuit with a roller-head pump (Cobe Cardiovascular, Arvada, Colo). Details of ECLS and anticoagulation management have been described previously. ${ }^{31}$ The patient received 5 units of packed red blood cells, 2 units of fresh frozen plasma, and 5 units of platelet concentrates during the course of ECLS. ECLS was discontinued after 72 hours, and the patient was extubated 3 days later. No complications occurred during ECLS. Chest radiography after ECLS revealed resolving bilateral patchy infiltrates (Figure 4).

The patient was discharged home on postoperative day 11. She delivered a healthy baby at 35 weeks gestation. 


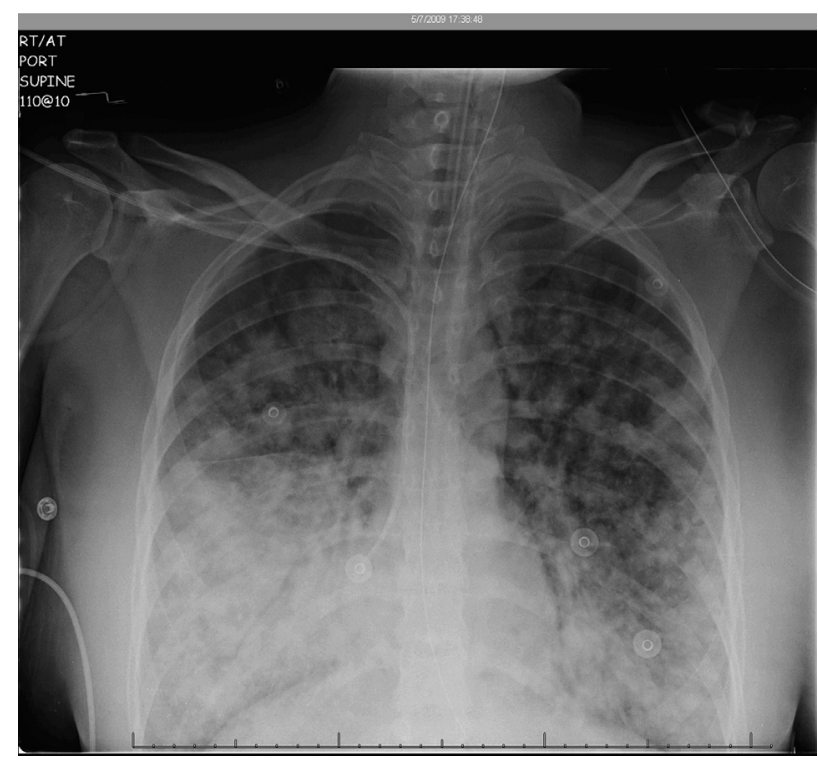

FIGURE 3. Portable supine anteroposterior radiograph of the chest obtained on admission, showing diffuse bilateral airspace opacities more predominant in the lower lobes. Given the provided history, the diagnosis was compatible with HCPS.

The mother and her son are alive and healthy 6 years after the event, with no sequelae noted from HCPS or ECLS therapy.

In a comprehensive case review of hantavirus pulmonary syndrome (HPS) during pregnancy in 5 women, Howard and colleagues ${ }^{32}$ summarized the presentation, clinical course, and outcome of 5 pregnant women with HPS. One maternal death and 2 fetal losses occurred. Gross, microscopic, and immunohistochemical examination for hantavirus antigen were done on 2 fetal autopsies and 3 placentas, and showed no evidence of transplacental hantavirus transmission. The authors concluded that HPS occurring during pregnancy may be life-threatening and result in fetal hypoxemic damage. The overall case fatality rate of HPS in a subset of patients who developed acute onset of respiratory failure and pulmonary edema was approximately $76.5 \% .^{32}$

HPS was first recognized in the Four Corners region of the southwestern United States in 1993, during an outbreak of unexplained deaths in previously healthy young individuals who developed acute onset of respiratory failure and pulmonary edema. Rapidly progressive acute pulmonary edema developed in 15 of the initial 17 patients $(88.2 \%)$ with confirmed infection from this newly recognized strain of hantavirus, and 13 patients $(76.5 \%)$ died, all of whom had profound hypotension. ${ }^{33}$ Because cardiogenic shock is responsible for most deaths, several investigators prefer the term HCPS over HPS. ${ }^{30}$

SNV has been identified as the etiologic agent of HCPS. It is carried by the deer mouse, Peromyscus maniculatus,

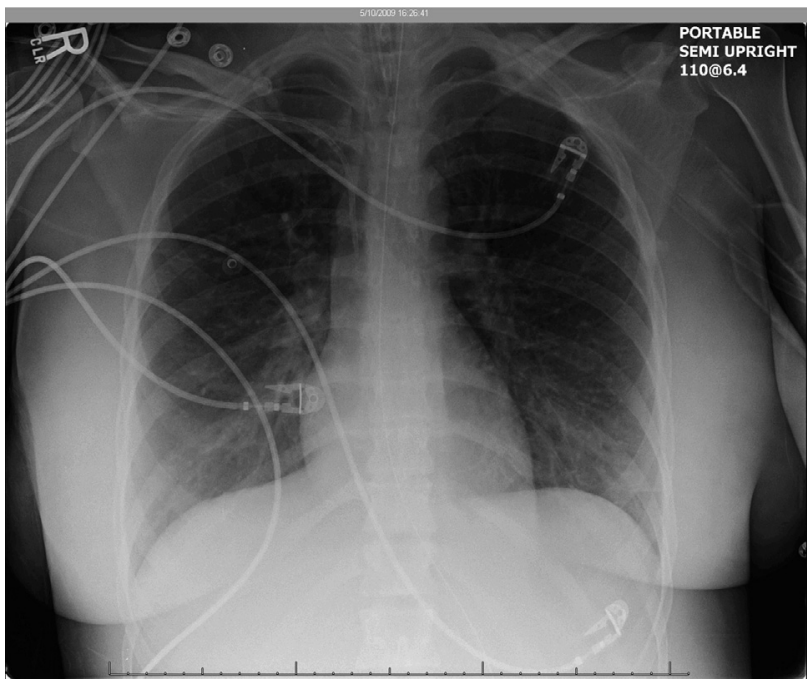

FIGURE 4. Portable supine anteroposterior radiograph of the chest obtained after 3 days of ECLS support, showing minimal bilateral lower lung ground-glass opacification consistent with residual airspace disease.

and is transmitted primarily through inhalation of urine and feces of contaminated rodents. ${ }^{33}$ Affected patients can be divided into 3 groups according to clinical course: (1) patients with a mild self-limiting form of the disease who remain hemodynamically stable; (2) patients who require mechanical ventilation and respond to inotropic support; and (3) profoundly hypoxic and hemodynamically unstable patients with cardiogenic shock who do not survive despite maximal conventional medical therapy. ${ }^{30}$

In 1998, Crowley and colleagues ${ }^{34}$ from the University of New Mexico Health Sciences Center reported their initial experience with the use of V-A ECMO as a rescue therapy in 3 patients with severe cardiopulmonary failure secondary to HCPS. Subsequently, our group reported in $2008^{31}$ and $2011^{35}$ an overall survival rate of $60.5 \%$ to $66.6 \%$ in patients with severe HCPS refractory to medical treatment, who had a predicted mortality of $100 \%$. The pregnant patient with HCPS who we report here was placed on V-A ECMO because of hemodynamic collapse and nonresponse to pressors and inotropes. To our knowledge, this is the first successful case of the use of ECLS in a pregnant patient with life-threatening HCPS.

\section{Study Limitations}

One limitation of using published reports is the likelihood of a bias toward better results, given that centers are less inclined to publish their bad outcomes. Furthermore, a proper statistical analysis was not feasible because of the small cohort of patients and the fact that the majority of the publications on ECLS or ECMO during pregnancy consisted of case reports or small case series. Another limitation of this report is that there was no control group, and the survival rate in the absence of ECLS is not known. 


\section{CONCLUSIONS}

In summary, ECLS during pregnancy is effective and relatively safe for the mother and fetus. Our study shows that ECLS during pregnancy is associated with survival rates of $77.8 \%$ ( 35 of 45 ) in mothers and $65.1 \%$ (28 of 43 ) in fetuses. In addition, we report the first successful use of ECLS in a pregnant patient with life-threatening HCPS, with no sequelae for the mother or fetus secondary to HCPS or ECLS therapy after 6 years of follow-up.

\section{Conflict of Interest Statement}

Authors have nothing to disclose with regard to commercial support.

\section{References}

1. Clark GP, Dobson PM, Thickett A, Turner NM. Chickenpox pneumonia, its complications and management: a report of three cases, including the use of extracorporeal membrane oxygenation. Anaesthesia. 1991;46:376-80.

2. Greenberg LR, Moore TR. Staphylococcal septicemia and adult respiratory distress syndrome in pregnancy treated with extracorporeal carbon dioxide removal. Obstet Gynecol. 1995;86:657-60.

3. Lee WA, Kolla S, Schreiner RJ Jr, Hirschl RB, Bartlett RH. Prolonged extracorporeal life support (ECLS) for varicella pneumonia. Crit Care Med. 1997;25:977-82.

4. King PT, Rosalion A, McMillan J, Buist M, Holmes PW. Extracorporeal membrane oxygenation in pregnancy. Lancet. 2000;356:45-6.

5. Satoh H, Masuda Y, Izuta S, Yaku H, Obara H. Pregnant patient with primary pulmonary hypertension: general anesthesia and extracorporeal membrane oxygenation support for termination of pregnancy. Anesthesiology. 2002;97: $1638-40$.

6. Cunningham JA, Devine PC, Jelic S. Extracorporeal membrane oxygenation in pregnancy. Obstet Gynecol. 2006;108:792-5.

7. Parkins MD, Fonseca K, Peets AD, Laupland KB, Shamseddin K, Gill MJ. A potentially preventable case of serious influenza infection in a pregnant patient. CMAJ. 2007; 177:851-3.

8. Scriven J, McEwen R, Mistry S, Green C, Osman H, Bailey M, et al. Swine flu: a Birmingham experience. Clin Med. 2009;9:534-8.

9. Singh K, Vasoo S, Stevens J, Schreckenberger P, Trenholme G. Pitfalls in diagnosis of pandemic (novel) A/H1N1 2009 influenza. J Clin Microbiol. 2010;48:1501-3.

10. Oluyomi-Obi T, Avery L, Schneider C, Kumar A, Lapinsky S, Menticoglou S, et al. Perinatal and maternal outcomes in critically ill obstetrics patients with pandemic H1N1 influenza A. J Obstet Gynaecol Can. 2010;32:443-52.

11. Robertson LC, Allen SH, Konamme SP, Chestnut J, Wilson P. The successful use of extra-corporeal membrane oxygenation in the management of a pregnant woman with severe H1N1 2009 influenza complicated by pneumonitis and adult respiratory distress syndrome. Int J Obstet Anesth. 2010;19:443-7.

12. Kunstyr J, Lips M, Belohlavek J, Prskavec T, Mlejnsky F, Koucky M, et al. Spontaneous delivery during veno-venous extracorporeal membrane oxygenation in swine influenza-related acute respiratory failure. Acta Anaesthesiol Scand. 2010;54:1154-5.

13. Dubar G, Azria E, Tesnière A, Dupont H, Le Ray C, Baugnon T, et al. French Registry on 2009 A/H1N1v During Pregnancy. French experience of 2009 A/H1N1v influenza in pregnant women. PLoS One. 2010;5:e13112.

14. Holzgraefe B, Broomé M, Kalzén H, Konrad D, Palmér K, Frenckner B. Extracorporeal membrane oxygenation for pandemic H1N1 2009 respiratory failure. Minerva Anestesiol. 2010;76:1043-51.

15. Nair P, Davies AR, Beca J, Bellomo R, Ellwood D, Forrest P, et al. Extracorporeal membrane oxygenation for severe ARDS in pregnant and postpartum women during the $2009 \mathrm{H} 1 \mathrm{N1}$ pandemic. Intensive Care Med. 2011;37:648-54.

16. Courouble P, Geukens P, Laarbaui F, Beauloye C, Van Caenegem O, Jacquet LM. Adult respiratory distress syndrome caused by 2009 H1N1 influenza during pregnancy: success of ECMO for both the mother and the child. J Extra Corpor Technol. 2011;43:75-8.

17. Panarello G, D’Ancona G, Capitanio G, Occhipinti G, Attardo G, Bertani A, et al. Cesarean section during ECMO support. Minerva Anestesiol. 2011;77:654-7.

18. Bowkalow S, Brauer M, Gross W, Schleussner E. Severe H1N1 infection during pregnancy. Arch Gynecol Obstet. 2011;284:1133-5.

19. Grasselli G, Bombino M, Patroniti N, Giuffrida A, Marcolin R, Vergani P, et al. Use of extracorporeal respiratory support during pregnancy: a case report and literature review. ASAIO J. 2012;58:281-4.

20. Takeda S, Kotani T, Nakagawa S, Ichiba S, Aokage T, Ochiai R, et al; Committee of Crisis Control, the Japanese Society of Respiratory Care Medicine and Committee of Pandemic H1N1 Surveillance, the Japanese Society of Intensive Care Medicine. Extracorporeal membrane oxygenation for 2009 influenza A (H1N1) severe respiratory failure in Japan. J Anesth. 2012; 26:650-7.

21. Seczyńska B, Jankowski M, Nowak I, Szczeklik W, Szułdrzyński K, Królikowski W. Pregnancy-related H1N1 influenza and severe acute respiratory distress syndrome successfully treated with extracorporeal membrane oxygenation despite difficult vascular access. Pol Arch Med Wewn. 2014;124: $136-7$.

22. Grimme I, Winter R, Kluge S, Petzoldt M. Hypoxic cardiac arrest in pregnancy due to pulmonary haemorrhage. BMJ Case Rep. 2012;2012:1-4.

23. Ngatchou W, Ramadan AS, Van Nooten G, Antoine M. Left tilt position for easy extracorporeal membrane oxygenation cannula insertion in late pregnancy patients. Interact Cardiovasc Thorac Surg. 2012;15:285-7.

24. Sim SS, Chou HC, Chen JW, Ma MH. Extracorporeal membrane oxygenation in maternal arrhythmic cardiogenic shock. Am J Emerg Med. 2012;30:1012.e3-5.

25. Sharma NS, Wille KM, Bellot SC, Diaz-Guzman E. Modern use of extracorporeal life support in pregnancy and postpartum. ASAIO J. 2015;61: $110-4$.

26. Duarte AG. ARDS in pregnancy. Clin Obstet Gynecol. 2014;57:862-70.

27. Guntupalli K, Karnad DR, Bandi V, Hall N, Belfort M. Critical illness in pregnancy, part II: common medical conditions complicating pregnancy and puerperium. Chest. 2015;148:1333-45.

28. Australia and New Zealand Extracorporeal Membrane Oxygenation (ANZ ECMO) Influenza Investigators, , Davies A, Jones D, Bailey M, Beca J, Bellomo R, Blackwell N, et al. Extracorporeal membrane oxygenation for 2009 influenza A (H1N1) acute respiratory distress syndrome. JAMA. 2009; 302:1888-95.

29. Paden ML, Conrad SA, Rycus PT, Thiagarajan RR. ELSO Registry. Extracorporeal Life Support Organization Registry report 2012. ASAIO J. 2013;59:202-10.

30. Koster F, Foucar K, Hjelle B, Scott A, Chong YY, Larson R, et al. Rapid presumptive diagnosis of hantavirus cardiopulmonary syndrome by peripheral blood smear review. Am J Clin Pathol. 2001;116:665-72.

31. Dietl CA, Wernly JA, Pett SB, Yassin SF, Sterling JP, Dragan R, et al. Extracorporeal membrane oxygenation support improves survival of patients with severe hantavirus cardiopulmonary syndrome. J Thorac Cardiovasc Surg. 2008;135:579-84.

32. Howard MJ, Doyle TJ, Koster FT, Zaki SR, Khan AS, Petersen EA, et al. Hantavirus pulmonary syndrome in pregnancy. Clin Infect Dis. 1999;29: 1538-44.

33. Childs JE, Ksiazek TG, Spiropoulou CF, Krebs JW, Morzunov S, Maupin GO, et al. Serologic and genetic identification of Peromyscus maniculatus as the primary rodent reservoir for a new hantavirus in the southwestern United States. J Infect Dis. 1994;169:1271-80.

34. Crowley MR, Katz RW, Kessler R, Simpson SQ, Levy H, Hallin GW, et al. Successful treatment of adults with severe hantavirus pulmonary syndrome with extracorporeal membrane oxygenation. Crit Care Med. 1998;26: 409-14.

35. Wernly JA, Dietl CA, Tabe CE, Pett SB, Crandall C, Milligan K, et al, Extracorporeal membrane oxygenation support improves survival of patients with hantavirus cardiopulmonary syndrome refractory to medical treatment. Eur J Cardiothorac Surg. 2011;40:1334-40.

Key Words: circulatory temporary support, extracorporeal membrane oxygenation, pregnancy 